\title{
Effects of starvation and mating status on the activity of the flea beetle, Phyllotreta nemorum (Coleoptera: Chrysomelidae)
}

\author{
Keiko OKU ${ }^{1,2,3}$, Kim M.C.A. VERMEER ${ }^{2}$, PAtrick VERBAARSCHOT ${ }^{2}$ and Peter W. De JONG ${ }^{2}$ \\ ${ }^{1}$ National Agricultural Research Center, 3-1-1 Kannondai, Tsukuba, Ibaraki 305-8666, Japan; e-mail: okeiko@affrc.go.jp \\ ${ }^{2}$ Laboratory of Entomology, Wageningen University, PO Box 8031, 6700 EH, Wageningen, The Netherlands; \\ e-mail: Peter.deJong@wur.nl \\ ${ }^{3}$ Laboratory of Evolutionary Ecology, Graduate School of Environmental Science, Okayama University, Okayama 700-8530, Japan
}

Key words. Chrysomelidae, Phyllotreta nemorum, female movement, flight activity, mating status, starvation

\begin{abstract}
Flea beetles are characterized by their tendency to jump. They can also fly. First, the effects of starvation on flight activity in the flea beetle, Phyllotreta nemorum L. (Coleoptera: Chrysomelidae) were determined. After starving P. nemorum for five days a greater number of individuals of both sexes flew than when fed continuously for the same period. In addition, the effect of the mating status of females of $P$. nemorum on their movement was determined. Mated females were more active than virgin females. It is concluded that starvation stimulates the flight activity of both sexes and mating activates the movement of females of $P$. nemorum.
\end{abstract}

\section{INTRODUCTION}

The flight activity of insects is affected by various factors, such as feeding condition. In some, but not all species, starvation stimulates flight activity (e.g., Elsey, 1974; Ferro et al., 1999; Moriya \& Hiroyoshi, 1998). Jumping behaviour is characteristic of flea beetles and is well studied (e.g., Furth et al., 1983; Furth \& Suzuki 1990, 1992). Although some species of flea beetle are apterous (e.g., Levesque \& Levesque, 1998), others, including Phyllotreta nemorum L. (Coleoptera: Chrysomelidae), can fly (e.g., Lamb, 1983). In the laboratory flight is rarely observed, which raises the question - what conditions stimulate flight activity in flea beetles? Although the kinematics of the flight behaviour of flea beetles has been studied (e.g., Brackenbury \& Wang, 1995) it is unclear what kind of physiological factors facilitate, or induce them to fly. Here, the effects of starvation on flight activity in $P$. nemorum are determined.

In addition, mating status often affects female movement; virgin females remain in areas where conspecific males are more likely to occur, whereas mated females do not (e.g., Julian \& Gronenberg, 2002; Petersson \& Sivinski, 2003). Thus, mating status may affect female movement (e.g., Shirai et al., 1998; Ferro et al., 1999). The effects of mating status on female movement in $P$. nemorum are reported here.

\section{MATERIAL AND METHODS}

\section{Flea beetles}

Flea beetle, Phyllotreta nemorum L. (Coleoptera: Chrysomelidae: Alticinae), is oligophagous feeding on a small number of plant species within the family Brassicaceae (Nielsen, 1977). Individuals of Phyllotreta nemorum were collected as larvae at Kvaerkeby and Try, Denmark in the summer of 2007 and reared on radish plants, Raphanus sativus L. (Brassicales: Brassicaceae), in a climate room $\left(24 \pm 5^{\circ} \mathrm{C}, 18 \mathrm{~L}: 6 \mathrm{D}\right)$ at
Wageningen University, the Netherlands. The larvae pupated in the soil and the adults that emerged from the soil were used in the following experiments. P. nemorum does not mate immediately after emergence (K. Vermeer, pers. observ.).

\section{Effects of starvation on the flight activity of $\boldsymbol{P}$. nemorum}

To examine whether starvation affects flight activity, 61 virgin males and 62 virgin females of $P$. nemorum were fed ad libitum for 2-3 d immediately after eclosion. Almost half of them were each separately placed in a test tube $(10 \times 74 \mathrm{~mm})$ only containing water-saturated cotton-wool (male $\mathrm{n}=30$, female $\mathrm{n}=30$, "without food"), and the remaining beetles in test tubes with two $R$. sativus cotyledons and water-saturated cottonwool (male $n=31$, female $n=32$, "with food"), the control. The test tubes were capped with dry cotton-wool and kept for 5 days at $25 \pm 5^{\circ} \mathrm{C}, 50-70 \%$ relative humidity, and a $16 \mathrm{~L}: 8 \mathrm{D}$ photoperiod (hereafter called "laboratory conditions") to acclimatize $P$. nemorum to the new conditions. Then, one $P$. nemorum individual at a time was placed on a closed Petri dish $(70 \mathrm{~mm}$ in diameter), which was put in the middle of a semitransparent plastic container $[410(\mathrm{~L}) \times 300(\mathrm{~W}) \times 220(\mathrm{H}) \mathrm{mm}]$. The behaviour of the beetle was recorded for $20 \mathrm{~min}$ and categorized as either: flying, jumping or walking/resting. When an individual beetle flew or jumped the observation ceased but continued for $20 \mathrm{~min}$ when it walked or rested. All observations were conducted between 11:00 AM and 17:00 PM at $25 \pm 5^{\circ} \mathrm{C}$. $P$. nemorum individuals were randomly assigned to a time for observation in order to minimize the effects on their activity. A new Petri dish was used for each observation. To determine whether sex and/or feeding condition had a significant effect on the flight activity of $P$. nemorum, the number of individuals that jumped and the number of individuals that walked or rested were combined. Then, the data were analyzed using a likelihood-ratio test. When an effect was significant at the 5\% level a $\chi_{2}^{2}$ test was used to compare treatments.

Effects of mating status on the activity of female $P$. nemorum

To determine whether mating status affects female movement 69 virgin adult females and 38 adult males were randomly picked from the stock culture. One female and one male were paired in each of a series of test tubes containing one $R$. sativus 


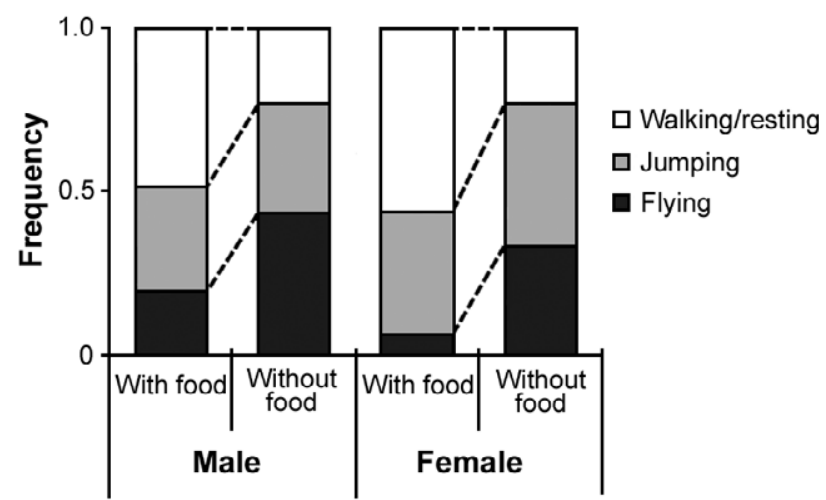

Fig. 1. Effect of starvation on the flight activity of Phyllotreta nemorum.

cotyledon and water-saturated cotton-wool ( $\mathrm{n}=38$, "mated female"), and the remaining females were placed singly in a second series of test tubes each containing one $R$. sativus leaf and water-saturated cotton-wool ( $\mathrm{n}=31$, "virgin female"). These test tubes were kept for $2 \mathrm{~d}$ under laboratory conditions. It was not confirmed whether mating occurred during the two days. Then, the $P$. nemorum females were individually transferred to new test tubes with only water-saturated cotton-wool and kept without food for 5 days under laboratory conditions. The four "mated" females that died during the five days were not included in the analysis. Then, the behaviour of each individual female was observed for $20 \mathrm{~min}$ in the same manner as described above. To determine whether female movement is significantly affected by mating status the number of individuals that flew and jumped were combined. Then, the data were analyzed using a $\chi^{2}{ }_{2}$ test.

\section{RESULTS AND DISCUSSION}

The flight activity of individuals of $P$. nemorum with and without food differed $(\mathrm{P}=0.006$, Table 1$)$. Although it did not differ between sexes $(\mathrm{P}=0.078)$, there was a tendency for males to be more flight active than females. In both sexes, more of the individuals that were not fed flew (male 43.3\%, female 33.3\%; Fig. 1) than of those provided with food (male $19.4 \%$, female $6.3 \%$; male $\chi^{2}=$ 4.087, $\mathrm{P}=0.043$; female $\left.\chi^{2}=7.276, \mathrm{P}=0.007\right)$. This indicates that starvation stimulates flight activity in $P$. nemorum. It is likely that hunger stimulates $P$. nemorum to fly in search of food.

The movement of females was affected by their mating status $\left(\chi^{2}=7.919, \mathrm{P}=0.005\right.$, Fig. 2$)$. The number of mated females that flew or jumped $(81.8 \%)$ was greater than of virgin females $(48.4 \%)$. As pupation of $P$. nemorum occurs in the soil, virgin females of $P$. nemorum may stay in areas where conspecific males are more likely to occur. In contrast, mated females do not need to wait for males. Thus, they may move elsewhere

TABLE 1. Results of a likelihood-ratio test of the effect of starvation on the flight activity of Phyllotreta nemorum.

\begin{tabular}{lcrc}
\hline & df & $\chi^{2}$ & P \\
\hline Sex & 1 & 3.108 & 0.078 \\
Food condition & 1 & 11.878 & 0.006 \\
Sex $\times$ food condition & 1 & 0.751 & 0.386 \\
\hline
\end{tabular}

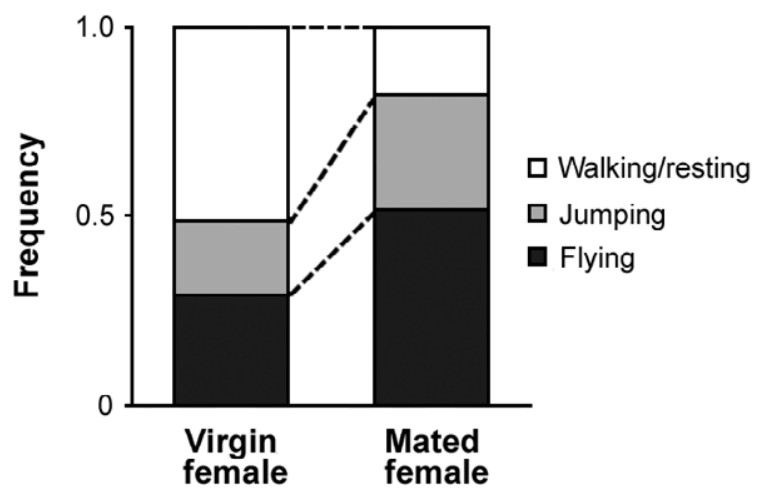

Fig. 2. Effect of mating on the activity of female Phyllotreta nemorum.

by flying or jumping. Mated females might need to search for oviposition sites. In the first experiment, virgin males and females were either fed or not fed, while in the second experiment both virgin and mated females were not fed. Therefore, the result for "female without food" in Fig. 1 should be similar to that for "virgin female" in Fig. 2. However, they appear to be different. The females used in these two experiments differed in age. In addition, although the first and the second experiments were done at the same place they were done at different times. These factors may have caused the discrepancy. In any case, the significant difference between treatments in the first experiment is a robust result.

Here, we focused on physiological factors affecting the flight activity of $P$. nemorum. However, the flight activity may be also affected by atmospheric factors, such as wind and temperature (e.g., Israd et al., 1999; Bonsignore \& Bellamy, 2007). Moreover, it is suggested that there is gene flow between populations of $P$. nemorum (Nielsen $\&$ de Jong, 2005). To better understand the life history of $P$. nemorum it is necessary to determine how long and frequently $P$. nemorum individuals actually fly and/or jump. These points remain to be studied in the future.

ACKNOWLEDGEMENTS. We thank M. Veldkamp and two anonymous reviewers for valuable comments, L. Koopman for rearing plants and T. Mitsunaga for advice on statistics. This study was partly supported by a grant from the Japan Society for the Promotion of Science for Young Scientists (no. 4537) to K.O.

\section{REFERENCES}

Bonsignore C.P. \& Bellamy C. 2007: Daily activity and flight behaviour of adults of Capnodis tenebrionis (Coleoptera: Buprestidae). Eur. J. Entomol. 104: 425-431.

BRACKENBURY J. \& WANG R. 1995: Ballistics and visual targeting in flea-beetles (Alticinae). J. Exp. Biol. 198: 1931-1942.

ELSEY K.D. 1974: Jalysus spinosus: effect of age, starvation, host plant, and photoperiod on flight activity. Environ. Entomol. 3: 653-655.

Ferro D.N., Alyokhin A.V. \& Tobin D.B. 1999: Reproductive status and flight activity of the overwintered Colorado potato beetle. Entomol. Exp. Appl. 91: 443-448.

FURTH D.G. \& SUZUKI K. 1990: The metatibial extensor and flexor tendons in Coleoptera. Syst. Entomol. 15: 443-448. 
FURTH D.G. \& SUZUKI K. 1992: The independent evolution of the metafemoral spring in Coleoptera. Syst. Entomol. 17: 341-349.

Furth D.G., Traub W. \& Harpaz I. 1983: What makes Blepharida jump? A structural study of the metafemoral spring of a flea beetle. J. Exp. Zool. 227: 43-47.

Israd S.A., Nasser M.A., Spencer J.L. \& Levine E. 1999: The influence of weather on western corn rootworm flight activity at the borders of a soybean field in east central Illinois. Aerobiologia 15: 95-104.

Julian G.E. \& GRONENBERG W. 2002: Reduction of brain volume correlates with behavioral changes in queen ants. Brain Behav. Evol. 60: 152-164.

Lamb R.J. 1983: Phenology of flea beetle (Coleoptera: Chrysomelidae) flight in relation to their invasion of canola fields in Manitoba. Can. Entomol. 115: 1493-1502.

LeVESQue C. \& LeVESQue G.-Y. 1998: Faunal composition, wing polymorphism and seasonal abundance of some flea beetles (Coleoptera: Chrysomelidae) in southern Quebec (Canada). Great Lakes Entomol. 31: 39-48.
Moriya S. \& Hiroyoshi S. 1998: Flight and locomotion activity of the sweetpotato weevil (Coleoptera: Brentidae) in relation to adult age, mating status, and starvation. J. Econ. Entomol. 91: 439-443.

NiELSEN J.K. 1977: Host plant relationships of Phyllotreta nemorum L. (Coleoptera: Chrysomelidae), I. Field studies. $Z$. Angew. Entomol. 84: 396-407.

NiELSEN J.K. \& DE Jong P.W. 2005: Temporal and host-related variation in frequencies of genes that enable Phyllotreta nemorum to utilize a novel host plant, Barbarea vulgaris. Entomol. Exp. Appl. 115: 265-270.

Petersson E. \& Sivinski J. 2003: Mating status and choice of group size in the phoretic fly Norrbomia frigipennis (Spuler) (Diptera: Sphaeroceridae). J. Insect Behav. 16: 411-423.

Shirai Y., Kosugi Y. \& Noguchi H. 1998: Effects of sex, mating status and temperature on flight activity of the Oriental tea tortrix, Homona magnanima (Lepidoptera: Tortricidae). Appl. Entomol. Zool. 33: 413-418.

Received March 23, 2010; revised and accepted April 19, 2010 